\title{
Telehealth for the Care of Complex Chronic Pediatric Patients in Latin America and the Caribbean: Narrative Review
}

\author{
María Celeste Savignano ${ }^{1}$ (1) - Graciela Kondratiuk ${ }^{2} \cdot$ María de las Mercedes Martínez $^{2} \cdot$ Pablo Lechuga $^{3}$. \\ Florencia Ugo ${ }^{4}$ - Mariel Della Corte ${ }^{2} \cdot$ Alejandro Mato $^{5}$. Antonio Luna ${ }^{6}$
}

Accepted: 30 June 2021 / Published online: 4 September 2021

(C) The Author(s), under exclusive licence to Springer Science+Business Media, LLC, part of Springer Nature 2021

\begin{abstract}
Purpose of Review This article is a review of the most significant productions on the care of pediatric patients with complex and/ or rare chronic diseases in the field of telehealth, produced in Latin America and the Caribbean. It inquires about accessibility to health, its efficiency for the care of chronic and rare diseases, its acceptability/resistance by users (health teams and patients), and the standardization-evaluation of telecare processes.

Recent Findings The formation of reference networks for patients with chronic and rare diseases.

Summary The incorporation of ICTs in comprehensive patient care is carried out mainly through home telemonitoring and the use of virtual platforms to empower patients and families. This modality allows to improve the attention and to offer assistance of specialties when there are geographic gaps. Telemedicine improves health outcomes, although article samples are mostly limited. It is made visible that the greatest impact in the region will be linked to the development of telehealth protocols and standards and legal and ethical frameworks, in order to guarantee good telehealth practices.
\end{abstract}

Keywords Telehealth $\cdot$ Telemedicine $\cdot$ Pediatrics $\cdot$ Complex chronic pathology $\cdot$ Rare diseases $\cdot$ Information and communication technologies (ICT) in health

\section{Introduction}

Children and adolescents with chronic and rare diseases have specific requirements for health services; this forces them to have specialized health teams and complex interventions. This leads to the need for recitations in health centers with the consequence of multiple transfers and frequent and/or

This article is part of the Topical Collection on Technology and Pediatrics

María Celeste Savignano

mcelsavignano@gmail.com

1 Líder de Proyecto de Telesalud, Coordinación de Redes y Comunicación a Distancia, Hospital de Pediatría SAMIC "Prof. Dr. Juan P. Garrahan", Combate de los Pozos, 1881 CABA, Argentina

2 Médica, Coordinación de Redes y Comunicación a Distancia, Hospital de Pediatría SAMIC "Prof. Dr. Juan P. Garrahan", Buenos Aires, Argentina

3 Comunicador Social, Coordinación de Redes y Comunicación a Distancia, Hospital de Pediatría SAMIC "Prof. Dr. Juan P.

Garrahan", Buenos Aires, Argentina prolonged hospitalizations. Another problem that they are faced with are those related to indirect costs for patients and their families, mentioning being uprooted due to the need to go to health centers far from their place of origin, increased underemployment and unemployment, and substantial financial burden affecting emotional, social, physical, and economic well-being [1-3].
4 Psicóloga Institucional Coordinación de Redes y Comunicación a Distancia, Hospital de Pediatría SAMIC "Prof. Dr. Juan P. Garrahan", Buenos Aires, Argentina

5 Administrativo, Coordinación de Redes y Comunicación a Distancia, Hospital de Pediatría SAMIC "Prof. Dr. Juan P. Garrahan", Buenos Aires, Argentina

6 Coordinador de Redes y Comunicación a Distancia, Hospital de Pediatría SAMIC "Prof. Dr. Juan P. Garrahan”, Buenos Aires, Argentina 
The care of children and adolescents with chronic and rare diseases, in any of their instances, be it diagnostic, follow-up, and/or treatment, constitutes one of the main challenges faced by both the pediatrician and the entire health system, since a change is needed to overcome the barriers produced by a care model oriented to the treatment of acute processes, with evident integration difficulties between the different levels of care as well as in the optimization of resources. Added to this, these pathologies collectively exert a global public health burden and generate accessibility barriers for those who suffer from them and their families in terms of the possibility of receiving adequate care in a timely manner.

There are various models to organize healthcare systems in a more integrated and proactive way, with the Chronic Care Model (CCM) and the Kaiser Permanente model (risk stratification) being the most influential [4]. In turn, the evolution of ICTs and their incorporation into health organizations allowed the planning and generation of new organizational and work models such as telemedicine care management. Initially, these models were proposed to overcome geographic access barriers and later incorporated the modality collaboratively between health teams [5].

In addition to this, and considering that information and communication technologies (ICT) today cross different fields and disciplines, their incorporation and use in the health sphere are essential and cannot be postponed. For two decades, telehealth strategies in Latin America and the Caribbean have increased significantly, especially in the context of the Sars-Cov-2 pandemic, and are closely related to digitization strategies and the strengthening of care networks.

To a greater extent, the initial literature on the subject addresses inequities in access to medical care, especially in geographically isolated or difficult-to-access areas, in addition to favoring the outreach to specialized care. An evaluation of the results of the inclusion of ICT in the development of telemedicine for the care of pediatric patients with complex and/or rare chronic diseases is necessary.

This article is a review of the most significant productions on the care of pediatric patients with complex and/or rare chronic diseases in the field of telehealth, produced in Latin America and the Caribbean, specifically inquires about as follows:

- Accessibility to care mediated by information and communication technologies

- The efficiency of remote medical care for chronic and rare diseases

- The acceptability/resistance by users (health teams and patients) of the ICT-mediated health care modality

- The standardization and evaluation of distance care processes mediated by ICT
To achieve this purpose and respond to the stated areas of interest, a general review of articles was carried out using open access databases (PubMed, LILACS, Scielo, and Cochrane) and subscribed and indexed (sites outside of PubMed), using the following key terms : telehealth, telemedicine, pediatrics, complex chronic, ICT, and rare diseases.

The following inclusion criteria were defined:

- Temporary: review of the last 5 years

- Language: articles in Spanish, Portuguese, or English

- Geographical: articles of studies carried out only in Latin American and Caribbean countries

- Thematic: articles on telehealth in complex chronic pediatric patients

The exclusion criteria were review articles, distance professional training programs, remote monitoring of suicide prevention, and patients in the pediatric intensive care unit.

Out of a total of 78 articles found, after reviewing the abstracts, only 13 articles met the inclusion and exclusion criteria. After reading it, 4 were excluded, so this review includes 9 articles in total.

\section{Revision}

The use of telemedicine has been a useful and accessible tool to provide at comprehensive treatment for all patients, a situation that has grown exponentially during the Sars-Cov-2 pandemic. Children and adolescents with chronic, complex, and/ or infrequent pathologies have not been the exception.

According to Marcolino and collaborators, after analyzing the use, effectiveness, and level of resolution of the remote consultation services provided to primary care units by the Telehealth Network of Minas Gerais, Brazil, they concluded that the teleconsultations prevented possible referrals in $80 \%$ of the cases, and $94 \%$ of the health providers reported satisfaction with the service received, which translates into a model for overcoming physical barriers in access to medical care for the entire pediatric population [6].

It is possible to cite several examples of chronic and/or complex pathologies that have benefited from their evolutionary control and follow-up through the use of telemedicine and applied technologies.

- According to Notejane et al., who have carried out a prospective study that was based on the telephone attention of patients being followed up by the palliative care service, they found that the satisfaction reported by parents and/or caregivers and the ability to avoid a face-to-face consultation position the telephone consultation as a healthcare resource to be considered, systematized, and improved in comprehensive care $[7 \bullet \bullet]$. Although, in our experience, 
there may be some benefit with telephone assistance interventions, such as containment of anxiety symptoms, in general terms, they may have little or no effect on caregiver's results compared to usual care.

- Telemedicine is a technological resource that allows the application of medicine from a distance, both for the diagnosis and the treatment of epileptic-type pictures as collected in the article of Garófalo Gómez and collaborators. Telemedicine includes fixed and mobile telephony, messaging, emails, and video calls through different digital tools. Telemedicine has been shown to be of no inferior quality to face-to-face consultations in relation to acute crisis control, hospitalizations, visits to emergency services, or adherence to medication, and it is more economical because it reduces the economic expenses and the time spent in the transfer to the hospital institutions or health centers $[8 \bullet \bullet]$.

- In the descriptive, retrospective study by Nieto-Ríos et al., a telemedicine care program is proposed for kidney transplant patients living in remote or rural areas. This study aims to improve and facilitate the care of patients who have difficulty accessing health services, with the same or better quality standards than conventional-face-to-face care and at a lower economic cost [9••].

- For Strickler and team, the follow-up of patients with juvenile idiopathic arthritis (JIA) under 16 years of age through a dual modality (face-to-face and distance) has made it possible to reduce transfers to health institutions, school absenteeism of boys, girls, or adolescent, and work of the parents, and the exacerbation of pain due to the prolonged transfers of patients who live far from the care centers $[10 \bullet \bullet]$.

- In the retrospective study by Guillén López et al., patients diagnosed with twenty-six types of innate errors of metabolism had better clinical and metabolic control than those who received remote care, added to the added value of the use of mobile care education applications for families [11••]. This study shows evidence on the possibility of applications for self-care and adequate monitoring of specific health needs. On the other hand, devices with these characteristics promote the bond of families with the health team and the continuity of follow-up. Nevertheless,

- According to Vera et al., remote telemonitoring emerges as an alternative for monitoring ventilatory therapy in systems of patients with home hospitalization, which consists of remote monitoring of all ventilatory therapy, and there are currently different tools to carry it out. Telemonitoring is defined as the transmission of physiological or noninvasive data through Bluetooth, digital, satellite, or Internet systems, their assessment, and storage [12••].

- Finally, we mention the work of Olivetti where the telemedicine project in congenital heart disease (CC) is explained within the National Congenital Heart Disease
Program (PNCC) of the Argentine Republic. It was observed that telemedicine represents an alternative that reaches the treating physician more effectively through remote consultation and response, optimizing correct diagnoses and timely referrals. In addition, it allows the dissemination of knowledge between low to high complexity centers, reduces asymmetries in diagnosis for patients residing in the interior of the country, avoids their unnecessary transfer, and strengthens networking [13••]. A similar situation occurred in Brazil through a telemedicine network for remote pediatric cardiology services in northeast Brazil that provided early detection protocols for heart defects through direct online supervision by a cardiologist. The times for diagnosis, transfer, and hospital stays were considerably reduced [14].

\section{Conclusions}

The health care models for children and adolescents with chronic and rare diseases focus on the comprehensive care of people, addressing general aspects of the disease, its epidemiology, diagnosis, treatment, and follow-up through various interventions, which include information and communication technologies. Its incorporation is used mainly for the telemonitoring (remote monitoring) of children with chronic diseases at home and in the use of educational virtual platforms, to empower the patient with regard to self-management of their care. In this way, it is the patient or his family who looks for the most appropriate way to make his own decisions regarding the management of his health.

There are articles that agree that telemedicine in this group of patients has the potential to improve care when geographic gaps are the main problem to be addressed and, above all, they highlight improvements in access to health services. Experiences that also incorporate the logic of health networks show greater benefits in terms of accessibility. In this sense, the integration of telehealth networks reduces inequities.

On the other hand, in the studies surveyed, it is also observed that this modality allows to provide assistance for specialties and/or subspecialties in places far from the centers where they are located, since most are concentrated in large cities.

Although telehealth practices have increased substantially in recent years, there is still little evidence that this type of care improves health outcomes. However, the study sample sizes are generally small. In other cases, results are reported considering the management of care by telemedicine but focused on a pathology or group of pathologies and addressed by a specialty. In this way, they fail to address the comprehensive care required by chronic and rare diseases. The experiences available in pediatrics are mainly focused on the care of children 
with congenital heart disease, treatment of chronic pain, among others. Another outstanding debt in the publications of Latin America and the Caribbean is the development of telehealth protocols and standards, as well as legal and ethical frameworks, for states to guarantee and control good telehealth practices, a development that is still incipient in the region.

This reality makes it necessary to increase studies and publications regarding the various dimensions addressed in this review.

\section{Declarations}

Conflict of Interest The authors declare no competing interests.

Human and Animal Rights and Informed Consent This article does not contain any studies with human or animal subjects performed by any of the authors.

\section{References}

Papers of particular interest, published recently, have been highlighted as:

•- Of major importance

1. Chen AY, Newacheck PW. Insurance coverage and financial burden for families of children with special health care needs. Ambulatory Pediatrics. 2006;6:204-9.

2. Kuhlthau K, Hill KS, Yucel R. y col. Carga financiera para familias de niños con necesidades especiales de atención médica. Salud infantil de Matern J. 2005;9:207-18. https://doi.org/10.1007/ s10995-005-4870-x

3. Kuo DZ, Houtrow AJ, Arango P, Kuhlthau KA, Simmons JM, Neff JM. Atención centrada en la familia: aplicaciones actuales y direcciones futuras en la atención de la salud pediátrica. Revista de salud maternoinfantil. 2012;16:297-305. https://doi.org/10. 1007/s10995-011-0751-7.

4. Bengoa R, Martos F, Nuño R, Kreindler S, Novak T, Pinilla R. Management models. In: Jadad AR, Cabrera A, Martos F, Smith $\mathrm{R}$, Lyons RF, editors. When people live with multiple chronic diseases: a collaborative approach to an emerging global challenge. Escuela Andaluza de Salud Pública: Granada; 2010.

5. Orruño Aguado E, Lapuente Troncoso JL, Gutiérrez Iglesias A, Asua BJ. Análisis de la introducción de la Telemedicina en la gestión/coordinación de Atención Primaria/especializada. Evaluación de resultados y costes de experiencias preexistentes (teleoftalmología). Madrid: Plan Nacional para el SNS del MSC. Servicio de Evaluación de Tecnologías Sanitarias del País Vasco; 2006.

6. Marcolino MS, Alkmim MB, Assis TGP, Sousa, de Lidiane AP, Ribeiro ALP. Teleconsultorias no apoio à atenção primária à saúde em municípios remotos no estado de Minas Gerais, Brasil /
Telehealth support for primary health care in remote municipalities in the state of Minas Gerais, Brazil. Rev. Panam. Salud Pública. 2014;35(5/6):345-52.

7.• Notejane M, Bernadá M. Atención telefónica en cuidados paliativos pediátricos: motivos de consulta y satisfacción de las familias. Archivos de Pediatría del Uruguay. 2021;92(1):e201. https://doi.org/10.31134/ap.92.1.2 This paper assesses the user satisfaction of parents and caretakers with the telephone communications as another assistance resource to be considered, systematized, and improved in comprehensive care.

8.• Garófalo Gómez N, Gómez García AM, González García S. Epilepsia pediátrica y telemedicina, una alternativa en tiempos de la COVID-19. Revista Cubana de Pediatría. 2020;92(Supl. 1): e1 186 This paper addresses the problem of a subgroup of patients chosen for the review in the context of COVID-19, through telemedicine as a technological resource that allows remote medicine for diagnosis and treatment of epileptic conditions.

9.• Nieto-Ríos JF, Diana Bello-Márquez C, Gaviria-Jiménez JJ, SernaHiguita LM. Impacto del lugar de residencia en la supervivencia de los pacientes con trasplante renal. ¿Puede la telemedicina mejorar este desenlace? Iatreia. 2021;1. https://doi.org/10.17533/udea. iatreia.120 This paper addresses the place of residence of patients as a determining characteristic for access to health care and proposes telemedicine as a possible answer.

10.• Strickler AS, Palma J, Charris R, Candia T, Grez M, González B, et al. Aporte del uso de herramientas básicas de Telemedicina en la atención de niños y adolescentes con Artritis idiopática juvenil, en el Hospital de Puerto Montt, Chile. Revista Chilena de Pediatría. 2018;89:59-66. https://doi.org/10.4067/S037041062018000100059 This study shows the advantages of the double care model (telemedicine and on-site consultation).

11.• Guillén López S, López Mejía L, Carrillo Nieto RI, Ibarra González I, Belmont Martínez L, Vela Amieva M. Atención de pacientes con errores innatos del metabolismo durante la pandemia de COVID-19 en México: importancia de la telemedicina. Acta Pediátrica de México. 2021;42:11. https://doi.org/10.18233/apm42no1pp11202141 This article shows that those patients with congenital metabolic diseases who had a remote follow-up improved their health conditions.

12.• Olivetti ME, Macarone S, Villa A. Primera experiencia en telemedicina dentro de un programa nacional. Medicina Infantil. 2019;26:151-5 This paper addresses the medical care work via telehealth modality with an integrated network of health services logic, through a program of national scope.

13.• Vera R, Reinero R, Torres-Castro R, Barros-Poblete M, Goncalves M. Telemonitorización del soporte ventilatorio domiciliario. Neumología Pediátrica. 2017;12:147-50 This paper presents home telemonitoring as an alternative for the follow-up of ventilatory therapy of patient systems.

14. Mattos SS, Vieira Hazin SM, Regis C, Soares de Araújo JS, Lira Albuquerque FC, Didier Nunes Moser LR, et al. A telemedicine network for remote paediatric cardiology services in north-east Brazil. Bull World Health Organ. 2015;93:881-7. https://doi.org/ 10.2471/BLT.14.148874.

Publisher's Note Springer Nature remains neutral with regard to jurisdictional claims in published maps and institutional affiliations. 